\title{
A cultura folclórica do boi-bumbá na escola: proposições para pensar uma ação pedagógica interdisciplinar
}

\author{
The folk culture of the boi-bumbá at school: propositions for thinking about an interdisciplinary \\ pedagogical action \\ La cultura popular del boi-bumbá en la escuela: propuestas para pensar una acción pedagógica \\ interdisciplinar
}

Recebido: 01/11/2021 | Revisado: 09/11/2021 | Aceito: 13/11/2021 | Publicado: 23/11/2021

\author{
Deny Ardaia da Silva \\ ORCID: https://orcid.org/0000-0002-1778-1398 \\ Instituto Federal de Ciência e Tecnologia de Rondônia, Brasil \\ E-mail: deny.silva@ifro.edu.br \\ Genivaldo Frois Scaramuzza \\ ORCID: https://orcid.org/0000-0003-3738-9905 \\ Instituto Federal de Ciência e Tecnologia de Rondônia, Brasil \\ E-mail: genivaldo@unir.br
}

\begin{abstract}
Resumo
Este artigo tem por objetivo, descrever a cultura folclórica do Boi-Bumbá no Instituto Federal de Ciência e Tecnologia de Rondônia - IFRO/Campus Cacoal e suas aproximações com a prática pedagógica escolar para o ensino interdisciplinar de Arte. Os sujeitos colaboradores foram professores/as e alunos/as desta instituição. A metodologia se deu pela abordagem qualitativa da bricolagem (Kincheloe, J. L. \& Berry, K. S. 2007) e usou várias técnicas de pesquisas amparadas pela perspectiva Pós-Crítica e pelos Estudos Culturais. A pesquisa com os docentes mostrou suas relações com o folclore em seus trabalhos monodisciplinares e os desejos de se voltarem para o campo da interdisciplinaridade. $\mathrm{O}$ trabalho junto aos estudantes forneceu dados sobre cultura popular e cotidianos. Essas informações auxiliaram na construção de uma Sequência Didática Interdisciplinar com o tema Boi-Bumbá e conteúdos dos componentes curriculares de Geografia, História, Sociologia, Educação Física, Língua Estrangeira Moderna/Espanhol, Língua Portuguesa/Literatura Brasileira e Arte e nos faz concluir que é possível integram os saberes da comunidade com os conteúdos oficiais e construir, interdisciplinarmente, uma educação intercultural em prol de uma sociedade democrática e inclusiva.
\end{abstract}

Palavras-chave: Boi-Bumbá; Culturas folclóricas; Arte; Práticas pedagógicas interdisciplinares.

\begin{abstract}
This article aims to describe the folk culture of Boi-Bumbá at the Federal Institute of Science and Technology of Rondônia - IFRO/Campus Cacoal and its approaches to the school pedagogical practice for the interdisciplinary teaching of Art. The collaborating subjects were professors and students of this institution. The methodology was based on the qualitative approach to bricolage (Kincheloe, J.L. \& Berry, K.S. 2007) and used several research techniques supported by the Post-Critical perspective and by Cultural Studies. The research with the professors showed their relationship with folklore in their monodisciplinary work and their desire to turn to the field of interdisciplinarity. The work with students provided data on popular culture and daily life. This information helped in the construction of an Interdisciplinary Didactic Sequence with the theme Boi-Bumbá and contents of the curricular components of Geography, History, Sociology, Physical Education, Modern Foreign Language/Spanish, Portuguese Language/Brazilian Literature and Art, and makes us conclude that it is possible integrate the knowledge of the community with the official contents and build, interdisciplinary, an intercultural education in favor of a democratic and inclusive society.
\end{abstract}

Keywords: Boi-Bumbá; Folk Cultures; Art; Interdisciplinary pedagogical practices.

\section{Resumen}

Este artículo tiene como objetivo describir la cultura popular de Boi-Bumbá en el Instituto Federal de Ciencia y Tecnología de Rondônia - IFRO / Campus Cacoal y sus aproximaciones a la práctica pedagógica escolar para la enseñanza interdisciplinaria del Arte. Los sujetos colaboradores fueron profesores y estudiantes de esta institución. La metodología se basó en el enfoque cualitativo del bricolaje (Kincheloe, J.L. \& Berry, K.S. 2007) y utilizó varias técnicas de investigación apoyadas por la perspectiva Postcrítica y por los Estudios Culturales. La investigación con los profesores mostró su relación con el folclore en su trabajo monodisciplinario y su deseo de volverse hacia el 
campo de la interdisciplinariedad. El trabajo con los estudiantes proporcionó datos sobre la cultura popular y la vida cotidiana. Esta información ayudó en la construcción de una Secuencia Didáctica Interdisciplinaria con el tema BoiBumbá y contenidos de los componentes curriculares de Geografía, Historia, Sociología, Educación Física, Lengua Extranjera Moderna / Español, Lengua Portuguesa / Literatura y Arte Brasileños, y nos hace concluir que es posible integrar el conocimiento de la comunidad con los contenidos oficiales y construir, interdisciplinar, una educación intercultural a favor de una sociedad democrática e inclusiva.

Palabras clave: Boi-Bumbá; Culturas populares; Arte; Prácticas pedagógicas interdisciplinarias.

\section{Introdução}

Os resultados aqui expressos, compõe um estudo amplo denominado: "A cultura folclórica do boi-bumbá no Instituto Federal de Rondônia - IFRO/Campus Cacoal: proposições para pensar práticas pedagógicas interdisciplinares” (Silva, 2021), que foi desenvolvida no Programa de Pós-Graduação Stricto Sensu em Educação Escolar - Mestrado e Doutorado Profissional do Departamento de Ciências da Educação da Fundação Universidade Federal de Rondônia. A construção dos dados empíricos foram produzidas no Instituto Federal de Educação, Ciência e Tecnologia de Rondônia - IFRO/Campus Cacoal, onde existe um Grupo Folclórico denominado Boi-Bumbá Brasileirinho que foi criado com o objetivo de complementar o componente curricular de Arte e envolver em suas apresentações temas transversais (PCNEM, 1997) como ética, saúde, meio ambiente, orientação sexual, trabalho, consumo, pluralidade e cultura, e assim, contribuir para a educação integrada dos estudantes.

No decorrer da pesquisa, tentamos descrever a cultura folclórica do Boi-Bumbá no IFRO/Campus Cacoal e suas aproximações com a prática pedagógica escolar; identificar as temáticas do folclore/cultura popular do boi-bumbá, descrever a historicidade deste processo como elemento de ensino e aprendizagem interdisciplinar; caracterizar os potenciais pedagógicos do folclore/cultura popular do boi-bumbá e suas aplicabilidades em sala de aula no componente curricular de Arte.

Ao final da pesquisa construímos uma proposta em forma de Sequência Didática Interdisciplinar, que poderá ser usada por outros professores sempre que necessário. No decorrer das pesquisas observou-se que existe um distanciamento entre os conhecimentos que a escola oferece e os saberes que os estudantes dominam. Por isso a proposta foi construída com a intenção de quebrar essa distância e, a partir dessa ideia, orientar os docentes que, antes de iniciar qualquer conteúdo em sala de aula, busquem conhecer os conhecimentos prévios que os estudantes possuem, quais as culturas que fazem parte de seus cotidianos e usar essas informações para construir seus planejamentos.

Para entender essa ausência ou distanciamento dos saberes que envolve o folclore/cultura popular na escola, utilizamos a metodologia da bricolagem que envolveu inúmeras técnicas de pesquisa como: pesquisas bibliográficas, documentais, entrevistas, reuniões, análise de imagens e vídeos entre outros. Essa abordagem tem inspiração nas Pedagogias Culturais que se alicerça no campo teórico dos Estudos Culturais (Giroux, 2019).

Pautamos as nossas ideias a partir da teoria da cultura de Hall (2013, p. 149) que "é definida como os estudos das relações entre elementos em um modo de vida global [...] Esta perpassa por todas as práticas sociais e constitui a soma dos inter-relacionamentos das mesmas”. Inspirado nessa compreensão, podemos dizer que o folclore/cultura popular passou a receber importância maior por parte dos intelectuais europeus na ocasião em que a Revolução Industrial põe em evidência as possibilidades de a cultura popular tradicional desaparecer (Burker, 2010, p. 26). As canções tradicionais e as velhas histórias, foram as primeiras modalidades a receber atenção por parte de alguns intelectuais, pois se elas faziam parte de um conjunto de coisas que representavam a identidade regional do povo europeu e perder essas características evidenciavam a diminuição do caráter de identidades nacionais que "não são coisas com as quais nós nascemos, mas são formadas e transformadas no interior das representações" (Hall, 2014, p. 48). A partir da contribuição do campo teórico dos Estudos Culturais e suas possibilidades de se articular a outras ciências em uma leitura interdisciplinar da cultura, pensamos ser importante expor a perspectiva metodológica que utilizamos neste estudo. 


\section{Metodologia}

A pesquisa se deu por uma abordagem qualitativa (Braun, 2019), porque é um campo amplo que, segundo Bogdan e Biklen (1994, p. 11), "alargou-se para contemplar metodologias de investigações que enfatizam a descrição, a indução, a teoria fundamentada e aos estudos das percepções pessoais", que sempre estiveram presentes no estudo da arte, na busca de compreender o processo criativo do artista, que é altamente sensório/subjetivo. Ademais, para Lima (2018, p. 2): "Enquanto os valores individuais, portanto, subjetivos são desprezados na pesquisa quantitativa, que centra sua atenção na objetividade, dos fatos palpáveis, o mesmo não ocorre quando se trata da pesquisa qualitativa".

A produção de dados foi gerada por uma perspectiva emergente apontadas pelos Estudos Culturais denominada de bricolagem (Neira \& Lippi, 2012), que se sustenta em várias estratégias de pesquisa e se caracteriza por um caráter eclético interdisciplinar (Kincheloe \& Barry, 2007).

A bricolagem aproveita diversos materiais diferentes que possibilitam a ampliação do campo de análise cultural, possibilita a comparação entre falas, experiências e produtos, pois: "Ao admitir a complexidade, a bricolagem constrói um papel muitíssimo mais ativo para os seres humanos, tanto ao moldar a realidade quanto ao criar os processos e as narrativas de pesquisa que a representam" (Kincheloe \& Barry, 2007, p. 17).

Além de análises documentais, como a observação do PPC de cursos específicos do Instituto Federal por meio da sistematização de compreensões sobre como as ementas de algumas disciplinas abordavam a temática da cultura popular, outras ferramentas foram acionadas para compor as estratégias de pesquisa. Com os/as professores/as utilizamos a técnica de entrevista virtuais, que oportunizou a cada um expor suas percepções em relação ao tema pesquisado, suas posturas diante da educação, da interdisciplinaridade, das condições de busca pelo estado de liberdade política dos seres humanos. Participaram dessas entrevistas professores dos componentes curriculares de História, Geografia, Sociologia, Educação Física, Língua Portuguesa/Literatura Brasileira, Língua Estrangeira Moderna/Espanhol e Arte/Música. Aplicamos um questionário semiestruturado com o intuito de compreender como esses componentes curriculares podem se articular ao ensino de Arte, como é a relação da escola com o folclore, quais as práticas pedagógicas voltadas ao folclore/cultura popular e, assim, compreender como o folclore/boi-bumbá se relaciona no IFRO/Campus Cacoal com esses componentes curriculares (Silva, 2021).

Como a pesquisa voltada aos estudantes tinha caráter de intervenção e a presencialidade estava impedida pela pandemia de Coronavírus, adotamos a técnica de reuniões virtuais e compartilhamos conhecimentos sobre cultura, folclore/cultura popular, boi-bumbá, cotidiano, experiências relacionadas ao fazer artístico/folclórico e aos saberes populares. Nessas reuniões o contexto do folclore/cultura popular abrangeu assuntos acerca da infância, na vivência familiar e sua relação com o saber popular conectado aos contos populares e lendas, alimentos e medicamentos caseiros; na vivência social abordamos as brincadeiras de infância, os registros de viagens; o trabalho da família, a convivência com os adultos; a liturgia das festas familiares; o entendimento do que venha ser sabedoria; a identificação e valorização das sabedorias existentes no núcleo familiar e o conhecimento das histórias antepassadas das famílias.

Além das entrevistas e reuniões, a bricolagem nos possibilitou fazer uso de pesquisas bibliográficas, documentais, análise de imagens e vídeos.

\section{Resultados}

Nas reuniões com os alunos o contexto do folclore/cultura popular abrangeu assuntos acerca da infância, na vivência familiar e sua relação com o saber popular relacionados aos contos populares e lendas, alimentos e medicamentos caseiros; na vivência social abordamos as brincadeiras de infância e outros assuntos relacionados (Silva, 2021). 
Nas entrevistas com os professores abordamos a relação do folclore com a escola, as práticas pedagógicas interdisciplinares voltadas para a cultura da comunidade e as dificuldades de agregar o saber do povo ao currículo oficial.

Por estarmos em período de pandemia por Covid19, todos os contatos foram realizados via plataforma Google Meet.

Diante disso, nos dispusemos a construir e propor a quem busca organizar um grupo folclórico dentro da escola uma Sequência Didática Interdisciplinar envolvendo o tema boi-bumbá: a cultura folclórica no campo pedagógico que foi inspirado nas estratégias elencadas em etapas e que contém "a apresentação da situação estudada, o produto inicial, a sequências do trabalho definidas por módulos e a produção final.” (Dolz, Noverraz, Schneuwly, 2004, p. 98). A Sequência Didática é um conjunto articulado e sistemático de atividades escolares que giram em torno de um tema de estudo.

Com as contribuições dos professores, por ocasião das entrevistas, começamos a pensar a Sequência Didática seguindo as etapas apresentadas por Dolz et al. (2004), dando ênfase às culturas e conhecimentos prévios que os estudantes têm e que podem trazer para a escola e colocando uma apresentação de boi-bumbá como o tema que irá atravessar os conteúdos dos componentes curriculares envolvidos na pesquisa e agora na Sequência Didática.

A visão que a maioria das pessoas tem de uma apresentação de boi-bumbá é que se trata apenas de brincadeira, de festa, de entretenimento (Dagnaisser, 2018), no entanto, essa apresentação pode se relacionar com vários saberes que podem atravessar conteúdos dos componentes curriculares, ampliando a cultura dos estudantes, da escola e da comunidade (Freitas, 2020).

A ausência da cultura popular na escola se deve ao silenciamento da cultura local (Grignon, 2019), regional, periférica - os saberes populares - pelo vício hegemônico, colonialista de que só pode ser visto como cultura o que pertence à elite. Pensando em quebrar esse silenciamento organizamos a Sequência Didática Interdisciplinar a partir da seleção de conteúdos dos componentes curriculares que constam no Ementário do IFRO/Campus Cacoal e que, se for aplicado, terá como produto o espetáculo de boi-bumbá de arena e que aparece no centro da Figura 1.

Figura 1. Fluxograma com uma ação pedagógica interdisciplinar com o tema Boi-Bumbá.

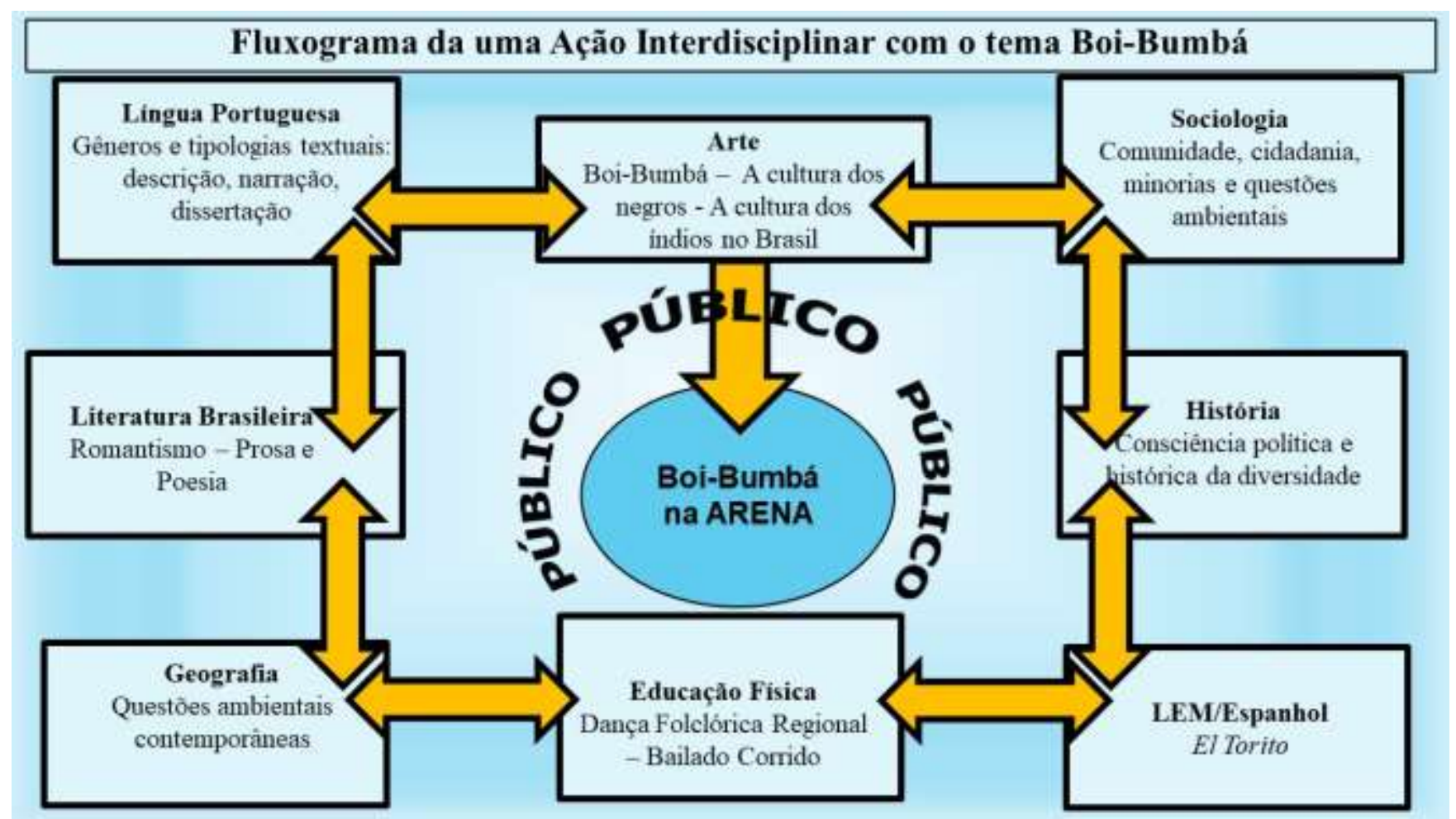

Fonte: Autores. 
A figura acima é um exemplo de ação pedagógica interdisciplinar com o tema Boi-Bumbá envolvendo componentes curriculares da Base Nacional Comum (2018) e conteúdos que permitem fazer esses atravessamentos. Neste exemplo há um direcionamento dos conteúdos ao tema de forma que resulte em um espetáculo de boi-bumbá de arena denominado "A Cultura dos Negros e a Cultura dos Índios Brasileiros". Este exemplo de fluxograma poderá ser aplicado em projetos interdisciplinares. "No caso de um espetáculo artístico cultural de boi-bumbá, este estudo poderá construir ideias para caracterização de personagens, para organizar sequências de trabalho na produção do enredo, da dança e da dramatização, na construção de croquis de fantasias, de adereços, de alegorias e outros elementos figurativos para o espetáculo ser exibido na arena." (Silva, 2021, p. 104).

No IFRO/Campus Cacoal o boi-bumbá se manteve, até o início da pandemia de Covid19, com o auxílio do Edital no 36/2018/CAC - CGAB/IFRO, de 11 de setembro de 2018, e está inativo até o momento por causa do isolamento social ocasionado pelos cuidados sanitários e devido a isso precisamos recorrer a técnica de entrevista com os professores/as e reuniões com os estudantes via plataforma Google Meet, que oportunizou a todos exporem suas percepções em relação ao tema estudado.

As apresentações do Grupo Folclórico do Boi-Bumbá Brasileirinho do IFRO/Campus Cacoal é uma hibridação composta pelo estilo do bumba-meu-boi do estado do Maranhão e do boi-bumbá de Parintins (AM). Está focando na cultura local com a intenção de criar sua própria identidade e integrar ao enredo, fantasias, adereços, cenários e alegorias temas do folclore local. Está agregado ao componente curricular Arte, mas é aberto a metodologias que envolvam outros componentes curriculares que fortaleça a interdisciplinaridade, incentive a prática pedagógica inovadora que descubra novos recursos para o ensino e para a aprendizagem da cultura dos estudantes. Amplie as possibilidades de permanência e êxito, fortaleça as manifestações culturais expandindo as relações humanas (Silva, 2021).

Reconhecer a importância do folclore e usar a sabedoria popular para valorizar a comunidade do entorno da escola possibilita ao docente ampliar a visão das situações reais, presentes, que fazem do contexto comunitário algo sólido e concreto, não necessitando recorrer a abstrações estranhas ou distantes do contexto local.

Como conteúdo implícito fortemente no contexto escolar, visto que a diversidade humana participante da educação formal é infinita e as políticas educacionais conceituam o direito e o dever de se reconhecer as diferenças, o folclore como manifestação social deve ser considerado como ponto de grande importância na elaboração de planejamentos [...] Sabendo das várias possibilidades para trabalhar qualquer conteúdo em sala de aula, planejar de maneiras diversificadas atividades que levem os alunos a entender processos culturais é papel do professor. $\mathrm{O}$ folclore, por si só, compreende um amplo campo de manifestações. Ora, como dito, as festas, músicas, danças, textos, e quaisquer outras características que possam mesclar história com o contemporâneo e surgir efeito implícito no povo, pode ser considerado folclore (Gonçalves \& Graupmann, 2017, p. 4).

A cultura artística brasileira é rica em exemplos de como as manifestações folclóricas se fazem presentes na vida dos brasileiros. São incontáveis os músicos, pintores, escultores, arquitetos que lançam mão de temas do folclore nacional para criar suas obras. Arte pode ser facilmente indicada como uma representante do folclore brasileiro, tudo isso fora dos muros da escola, mas que facilmente pode ser encampada por ela, apenas precisamos fundamentar essa ideia juntamente com os professores/as.

Os conhecimentos que a escola valoriza, de maneira geral, são os conhecimentos técnicos, teóricos, históricos e seu interesse é formar para o mercado de trabalho. Em âmbito de conhecimento artístico e cultural a estrutura educacional valoriza mais a questão dos conteúdos acadêmicos em si e menos o fazer arte e folclore. Na hora de decidir o que aplicar do currículo a unidade escolar se põe neutra, aposta nas opções que vêm do sistema educacional e aplica. Essa atitude de neutralidade da escola que recai, especificamente, na sala de aula, talvez seja um dos sinais da opressão nas culturas silenciadas. 
Sobre essa neutralidade que leva as instituições, por meios de seus gestores e professores, a apontarem as culpas em outras direções, Santomé (2019, p. 164), afirma o seguinte:

Nas instituições de ensino não se costuma considerar essa forma de opressão como objeto de atenção prioritária. É frequente que tanto as autoridades políticas quanto os professores e professoras se vejam a si mesmos/as como pessoas objetivas, neutras e, por conseguinte, como pessoas que não favorecem a reprodução e produção de comportamentos racistas. Entretanto, quando se faz análise etnográfica no interior das salas de aula ou se observam os materiais curriculares, logo aparecem, diante de nossos olhos, condutas que invalidam as autoimagens de neutralidades que o sistema educacional oferece.

Precisamos fortalecer as práticas pedagógicas voltadas para a concretude (Freire, 1981, 1992, 1996, 2011), para a compreensão da cultura e do cotidiano dos estudantes e para a relevância do contexto na educação (Barbosa, 2010). Precisamos quebrar as barreiras entre o erudito e o popular, dar mais importância a cultura viva, pois, "a destruição da história é essencial para dominação de uma nação por outros povos.” (Barbosa, 2011, p. 3).

Os conhecimentos que fazem parte da cultura de nossos estudantes, e que já vistos por eles mesmos como pouco importantes, os enquadram em grupos sociais majoritários. A educação formal invalida esses conhecimentos gerando silenciamento dessas culturas e anula sua importância, sua força e a sua grandiosidade.

\section{Discussão}

A partir de diálogos com a comunidade escolar - professore e estudantes, percebemos que existe uma luta diária entre a inovação curricular propostas pelas tendências pedagógicas progressistas e o sistema educacional vigente que é fortalecido pelos interesses econômicos/políticos e, portanto, é resistente às mudanças ocasionadas por possibilidades de troca de poder entre um sistema que vislumbra a melhoria social e o outro que mantém o poder da econômica nacional/internacional, dos meios pelo qual a informação é disseminada e usa esse domínio para fortalecer uma educação hegemônica e silenciadora das culturas populares.

Como na maioria das vezes, o folclore/cultura popular depende apenas das manifestações orais para serem repassadas às novas gerações e o boi-bumbá é uma manifestação, que remonta ao século XVII, e atualmente está presente em quase todos os estados brasileiros. Não sabemos ao certo qual sua origem, entretanto acreditamos que seja análoga ao surgimento das danças de quadrilhas que imitam de forma cômica as festas que aconteciam nas casas dos Senhores de Engenhos. Esta presença do boi-bumbá na cultura brasileira representa a força da oralidade na transmissão dos saberes populares que mesmo estando diante de um sistema silenciador, consegue manter-se vivo mesmo em condições desiguais em relação a dita cultura erudita. Muitos pesquisadores tentam trilhar a genealogia da festa do boi, mas sempre se deparam com eventos incertos que apontam para outros caminhos, inclusive de que o início deste folguedo aconteceu em outros países. Na literatura aparece pela primeira vez no final do século XIX como explica Nakanome (2017, p. 18):

Os primeiros registros sobre o bumbá indicam os passos da brincadeira que se espalhou por todo o território nacional, mas que caminha principalmente entre o Nordeste e o Norte. Em 1840, o Jornal "O Carapuceiro", de Recife, publicou matéria em que o frei beneditino Miguel do Sacramento Lopes Gama tece pesados comentários sobre o folguedo, chegando, inclusive, a considerá-lo "tolo, estúpido e destituído de graça, um agregado de disparates". Em registro datado de 1859, o segundo feito em Manaus, Avé-Lallemant relata a introdução de um "cortejo pagão" dentro da festa da instituição católica. Esta importante passagem é considerada a segunda referência escrita sobre o boi no Brasil e compreende também um mapa cultural, onde o elemento bumbá se destaca. 
Muitos grupos folclóricos nascem em escolas, mas a estrutura da escola nem sempre garante a manutenção dos grupos. Os grupos folclóricos que não são da escola, geralmente persistem com mais facilidades, são mais resistentes e vivem a tradição que, geralmente é passado de pai para filho e por isso mantém uma profissionalização mais evidente.

A partir da década de 60 passou-se a estudar a pedagogia apoiada nas relações culturais, políticas e de poder, tal abordagem se deve à aproximação dos Estudos Culturais a educação (Andrade \& Costa, 2015) surgindo assim o conceito de Pedagogias Culturais que se permitiu discutir artefatos da cultura e processos educativos, ao contrário do que vinha se fazendo durante muito tempo, onde a cultura era apresentada como um campo rígido, dominante e limitado a autores e obras com "repertórios mais ou menos canônico [...] que era preciso levar a sério, conhecer, apreciar, conservar e transmitir de geração em geração, uma cultura legítima e, de certa maneira, obrigatória.” (Domingues, 2011, p. 403). Dessa aproximação começaram a surgir ideias como as sugeridas por Kretli (2007, p. 2) ao afirmar que:

Na contracorrente da posição hegemônica, os professores precisam resgatar a sua competência de sujeitos criativos, autores de saberes e fazeres contrários à repetição e à reprodução de uma ordem social injusta e de uma proposta curricular pré-estabelecida e descontextualizada da realidade sociocultural dos alunos: uma proposta curricular que tem demonstrado ser abstrata e sem sentido.

A partir daí, começam a surgir outros questionamentos a respeito do currículo, da sua função e sua intenção. No sentido de apontar o seu uso de forma repetitivo, reprodutivo das mesmas ideias, mantenedor de injustiça social e descontextualizador dos fatos históricos os Estudos Culturais, por intermédio das Pedagogias Culturais, começa a evidencia a existência de outras pedagogias que não fazem parte do universo escolar e que atinge, por meio dos artefatos culturais, de forma mais objetiva, mais concreta e mais significativa, os cidadãos.

Com a aproximação dos Estudos Culturais da Educação (Andrade \& Costa, 2015), a visão da prática pedagógica foi ampliada por se perceber a forte influência das múltiplas dimensões da vida ativada pela articulação entre pedagogia e cultura, mas, o processo de apropriação das pedagogias culturais pela escola é bastante lento e muito avançado no processo de apropriação do poder política e econômico em prol da imposição da dita cultura de elite.

É comum vermos discursos em prol da unificação educacional pelos sistemas educacionais no afã de se cumprir à risca os conteúdos sistematizados indicados como importantes para a manutenção da cultura hegemônica multiculturalista de abordagem assimilacionista (Lima \& Suanno, 2013), que dificulta a qualquer mudança do sistema educacional tradicional em prol da inclusão de atividades pedagógicas voltadas para a cultura dos estudantes.

Artefatos culturais favoráveis aos objetivos governamentais pregam o pensamento multiculturalismo assimilacionista, que corrobora com a ideia de que "todos se integrem na sociedade e sejam incorporados à cultura hegemônica" (Candau, 2008, p. 50), agem contra a cultura da maioria da população brasileira. O próprio Programa Nacional do Livro Didático - PNLD impõe aos professores os livros que as editoras com maior aporte financeiro oferecem e que só dialogam com os interesses das classes dominantes contrário à educação contemporânea intercultural e que, a ver de Candau (p. 51) é "a mais adequada para a construção de sociedades, democráticas e inclusivas, que articulem políticas de igualdade e políticas de identidade”, que incentivem a criação de livros didáticos voltados a realidade das comunidades brasileiras.

É necessário dar continuidade a estudos que esclareçam e apontem soluções para a problemática da falta de diálogo entre os livros didáticos usados em nossas escolas e a cultura de nossos alunos, que é desprivilegiada e colocada em escanteio, perdendo sua evidência e expressão devido ao valor dado a culturas alheias, que nos são apresentadas por diversas mídias, possibilitando assim a formação de preconceitos velados que se refletem na não aceitação da própria identidade cultural e de suas origens, envergonhando-se e se sentido inferior às pessoas que vivem nas metrópoles, exemplificadas pelos livros didáticos utilizados por nossas escolas (Silva, 2021, p. 40). 
Pensamos o boi-bumbá na escola como artefato cultural, pois o enredo do "Auto do Boi" referenda uma relação de poder, de conflito político, étnico e de luta por territórios. Tem possibilidades de motivar estudos junto aos estudantes sobre fatos, costumes, lendas, mitos, crenças, saberes e fazeres da comunidade ao entorno da escola e agregar o resultado desses estudos a esse enredo (Silva, 2021). Além disso, enquanto educadores, devemos "reforçar a herança artística e estética dos alunos com base em seu meio ambiente (Lima, 2020) e o universo cultural da comunidade. "Barbosa (1991, p. 34).

A aproximação da escola com o folclore/cultura popular fortalece relações interculturais que equilibram os saberes propostos pelo sistema com os saberes que a comunidade tem a oferecer, e dessa forma, ambos contribuem para a efetivação da identidade do local e dos membros dessa comunidade. Pois, além dessa efetivação identitária, também agiliza o processo de hibridação cultural (Lima \& Suanno, 2013) que promove uma via de mão dupla de troca de conhecimentos entre escola e comunidade.

Nesse campo, onde o as manifestações folclóricas brasileiras perdem espaços incentivadas, principalmente, pela mídia e promovidas pelos artefatos culturais que ela apresenta, podemos fazer uma comparação rápida entre o dia 22 de agosto, dia do folclore brasileiro e o dia 31 de novembro, data que se comemora o halloween - manifestação folclórica estadunidense. Esta última recebe evidência maciça da mídia brasileira, enquanto que o nosso folclore, independente de data, é silenciado. Existe um sistema interessado que isso ocorra e talvez seja o mesmo sistema que tem interesse em fazer uma educação hegemônica e silenciadora das populações dominadas.

Nas entrevistas tivemos falas que apontam para essa postura afirmando que o folclore brasileiro, apesar de sinalizar práticas cheias de saberes populares, está ausente da escola porque já sofremos os efeitos da educação silenciadora que ocorre em nosso país. Por exemplo, o professora PLPL051 afirmou que "a gente sempre acha que o do outro é melhor, principalmente, o que vem do estrangeiro, da Europa, dos Estados Unidos, portanto faz parte de uma questão de valorização"; o professor PS02 afirma que: "essa ausência se deve ao fato de existir uma compreensão por parte da academia de que a cultura popular precisa passar pelo crivo das ciências de laboratório. É como se essas culturas tivessem que pedir bênçãos para entrar na escola"; e o professor PH04 disse que "as pessoas não valorizam a cultura local" e devido a isso o sistema educacional, que tem objetivos elitistas ganha espaço e impõe suas estruturas educacionais no currículo. (Silva, 2021).

Nas reuniões com os estudantes, eles se manifestaram a favor do folclore brasileira na escola e apontaram várias sabedorias importantes para a cultura local que passa pelo entretenimento, culinária, medicina popular, mitos e crenças. Eles entendem que esses saberes são rejeitados/excluídos pela escola por se achar que não é cultura, mas que graças a seus familiares, principalmente aos mais velhos, eles conseguiram aprender muito sobre essas práticas, mas entendem que aos poucos os saberes vão desaparecendo (Silva, 2021). Segundo a aluna $E^{2}$, “a nossa geração está se tornando muito independente, sozinhos, com o telefone ali, um pouco mais virtual, então, eu acho que a gente está ficando muito individualista".

$\mathrm{Na}$ fala desses estudantes, fica perceptível a ideia de que estamos nos desconectando das sabedorias dos mais velhos e como consequência disso, estamos nos isolando. Ampliamos nossos meios de informações, mas nos distanciamos mesmo estando, fisicamente, próximos (Silva, 2021). Sobre isso o aluno F, disse o seguinte:

Hoje em dia se você se reúne com as pessoas ninguém conversa com ninguém, todo mundo no telefone, então a gente acabou se alienando ... acabou deixando a essência que vem de antigamente, que é de você sentar e conversar. Eu tenho primos e parentes que você vê que hoje mora dentro da casa e não conversa com seu pai ou não conversa com sua mãe ou simplesmente, vive no celular. Se precisar de alguma coisa estando dentro da própria casa manda um whatsapp para a mãe ou para o pai para conversar e não levanta, não vai até o lugar para poder falar pessoalmente ... a

\footnotetext{
${ }^{1} \mathrm{O}$ nome foi substituído por direito ao anonimato.
}

${ }^{2}$ Idem 
essência de você conversar olho no olho, a conversa pessoalmente está acabando ... deixando a essência de ser um ser humano e passando a ser máquinas.

A partir da fala desses estudantes, constatamos de forma genérica, que a sabedoria ocasionada pelas experiências vividas por eles é profunda e representa o sentido da tradição passada pela oralidade, uma vez que os mesmos demonstram que aprenderam com seus familiares mais velhos e é interessante observar que todos têm algo a ensinar independentemente da idade. Acreditamos que em algum momento esse saber ficará em evidência. Essas reuniões nos fizeram observar suas culturas, seus valores, suas preocupações com as gerações vindouras e com o futuro da humanidade.

\section{Considerações Finais}

Entendemos que há uma relação muito próxima do folclore com a escola por existir uma força entre herança artística, histórica e cultural que envolve relações de conhecimento. As entrevistas com os professores indicaram que mesmo existindo um distanciamento entre currículo e realidade cultural dos alunos, temos professores/as resistentes ao sistema que fazem, mesmo que de forma monodisciplinar, ações pedagógicas voltadas para o folclore.

Entendemos que em um cenário que envolvesse situações interdisciplinares, esses trabalhos teriam maiores resultados que gerariam culminâncias em espaços maiores, para um público maior.

Com suas falas, os professores entrevistados, passaram a ideia de que entendem como ocorre o processo interdisciplinar de ensino, reconhecem em vários componentes curriculares inúmeras possibilidades de ensino que abarcam o folclore/cultura popular como grandes possibilidades de práticas pedagógicas interessantes, mas se sentem presos às ementas oficiais, à pressão impositiva do corpo técnico escolar que os prendem aos currículos e programas, e por isso, acabam usando todo o tempo que dispõem na instituição para aplicar suas aulas e cumprir trabalhos administrativos, conforme o sistema exige.

A brincadeira de Boi-de-Bumbá se organizada e planejada dentro dos moldes acadêmicos que a instituição escolar adota, pode acessar o saber científico e transformá-lo em artefato cultural prazeroso e significativo para a educação dos alunos, dos professores e da comunidade no entorno da escola. Os professores compreendem a necessidade de fazer a conexão entre os conteúdos apresentados em seus ementários e o cotidiano dos alunos. Sabem que é necessário manter o sentido de concretude, mas sentem-se desamparados pelo sistema estruturalmente organizado, que segue à risca as orientações das esferas maiores que regulam as atividades pedagógicas. Nesse sentido, eles alegam que não há como ampliar os trabalhos que visem uma sustentação maior na cultura da comunidade mesmo com a intenção de fazê-lo. Ainda assim, os professores/as demonstraram nas ações pedagógicas relacionadas por eles várias atividades voltadas para o saber do povo e envolvendo a cultura.

Os professores dão grande importância ao folclore/cultura popular para a comunidade pois este aponta para o sentido das identidades, localização, pertencimentos, valores e outras características do povo brasileiro. Compreendem a necessidade de o folclore/cultura popular se fazer presente no cotidiano da escola, mas enxergam um certo distanciamento em relação aos reais objetivos da escola. Percebem que esse distanciamento caracteriza a escola como algo estranho ao aluno e que essa estranheza recai sobre o academicismo tão valorizado pelas instituições educacionais.

Em relação ao folclore/cultura popular, os/as entrevistados/as afirmam que é uma prática de conhecimento constante devido às transformações que ocorrem por força dos avanços tecnológicos e por perceberem que mesmo assim, muitos desses conhecimentos permanecem gerando novos conhecimentos.

Nas reuniões com os estudantes, eles disseram que gostam de brincar de boi, que foram felizes brincando e desejam essa felicidade para outros alunos e outras pessoas, só veem boas perspectivas para as apresentações do Grupo Folclórico BoiBumbá Brasileirinho e afirmam que é preciso levar esse espetáculo a outros públicos. Eles se dispuseram, caso estejam por perto, a contribuir com os trabalhos. Afirmaram também, que não haviam participado de nada semelhante pelas escolas por 
onde estudaram, mas mostraram uma infinidade de saberes que adquiriram em suas famílias e que podem ser usados para a criação de roteiros para tematizar as apresentações do boi-bumbá com lendas, mitos, brincadeiras, costumes e crenças populares, como também, preservação do meio ambiente, defesa de etnias minoritárias, campanhas contra o racismo, machismo, sexismo e outros que porventura seja apontado como tema importante para a comunidade.

\section{Referências}

Andrade, P. D. \& Costa, M. V. (2015). Usos e possibilidades do conceito de pedagogias culturais nas pesquisas em estudos culturais em educação. Textura. Canoas, 17, (34), 48-63.

Barbosa, A. M. (2014). A imagem no ensino da arte: anos 80 e novos tempos. (9a ed.), Perspectiva.

Barbosa, A. M. T. B. (2010). Arte e cultura visual. In: Anais do XXX Colóquio do Comitê Brasileiro de História da Arte.

Barbosa, A. M. (2011). A cultura visual antes da cultura visual. Educação, 34, (3), 293-301.

Bogdan, R. C. \& Biklen S. K. (1994). Investigação qualitativa em educação - Uma introdução à teoria e ao método. Porto Editora/LDA.

BRASIL. (2018). Ministério da Educação. Base nacional comum curricular.

Brasil (2013). Diretrizes curriculares nacionais gerais da educação básica. Ministério da Educação. Secretaria de Educação Básica. Diretoria de Currículos e Educação Integral. MEC, SEB, DICEI.

Braun, V. et al. (2019). Coletas de dados qualitativos: um guia prático para técnicas textuais, midiáticas e virtuais. Vozes.

Burke, P. (2010). Cultura popular na Idade Moderna: Europa 1500-1800. Tradução: Denise Bottmann. Companhia das letras.

Candau, V. M. (2009). Educação escolar e culturas: multiculturalismo, universalismo e currículo. In: Candau, Vera Maria (Org.). Didática: questões contemporâneas. (pp. 47-60). Forma \& Ação.

Dagnaisser, D.C. P. (2018). Para além do espetáculo: Folclore e patrimônio nos bois-bumbás de Parintins-AM. Dissertação. Programa de Pós-Graduação Interdisciplinar em Ciência Humanas da Universidade Estadual do Amazonas - UEA.

Dolz, J.; Noverraz, M. \& Scnheuwly, B. (2004). Sequências didáticas para o oral e a escrita: apresentação de um procedimento. In: Scnheuwly. B; Dolz, J. Gêneros orais e escritos na escola. Mercado de Letras.

Domingues, P. (2011). Cultura popular: as construções de um conceito na produção historiográfica. História, 30, (2), $401-419$.

Freire, P. (1981). Ação cultura para a liberdade. Paz e Terra.

Freire, P. (1992). Pedagogia da esperança. Paz e Terra.

Freire, P. (2002). Pedagogia da autonomia: Saberes necessários à prática educativa. Paz \& Terra.

Freire, P. (2011). Pedagogia do oprimido. Paz e Terra.

Freitas, R. G. (2020). Princípio do progresso e criatividade na produção do espetáculo do boi-bumbá de Parintins/AM. Dissertação Mestrado em Administração - Universidade Federal do Espírito Santo, Centro de Ciências Jurídicas e Econômicas.

GIROUX, H. A. (2019). Praticando estudos culturais nas faculdades de educação. In: Silva, T.T. (Org.) Alienígenas na sala de aula: uma introdução aos estudos culturais em educação. (pp. 85-100), 11. Ed. Rio de Janeiro: Vozes.

Gonçalves, F. K. \& Graupmann, E. H. (2017). O ensino do folclore nas escolas: a perspectiva de docentes dos anos iniciais do ensino fundamental. https://educere.bruc.com.br/arquivo/pdf2017/25878_13431.pdf.

GRIGNON, C. (2019). Cultura dominante, cultura escolar e multiculturalismo popular. In: Silva, T.T. (Org.) Alienígenas na sala de aula: uma introdução aos estudos culturais em educação. (pp. 173-183), 11. Ed. - Vozes.

Hall, S. (2014). A identidade cultural na pós-modernidade. DP \& A.

Hall, S. (2013). Da Diáspora - Identidades e mediações culturais. Editora UFMG.

Kincheloe, J. L. \& Berry, K. S. (2007). Pesquisa em educação: conceituando a bricolagem. Porto Alegre: Artmed.

Kretli, S. (2007). Artefatos culturais usados por professores/as e alunos/as no cotidiano escolar como possibilidades de ressignificar o currículo. Anped Associação Nacional de Pós-Graduação e Pesquisa em Educação. https://anped.org.br/sites/default/files/gt12-3217-int.pdf.

Lima, J. J. L. \& Suanno, M. V. R. (2013). Perspectiva Multi/Intercultural e Educação Superior. Revelli - Revista de Educação, Linguagem e Literatura de Inhumas. 5, (2), 110-118.

Lima, R. S. et al. (2020). Educação escolar em comunidades quilombolas no Vale do Rio Guaporé: uma análise a partir do Referencial Curricular de Rondônia, Brasil. Research, Society and Development, 9, (7). 
Research, Society and Development, v. 10, n. 15, e165101522641XX, 2021

(CC BY 4.0) | ISSN 2525-3409 | DOI: http://dx.doi.org/10.33448/rsd-v10i15.22641

Nakanome, E. S. (2017). A representação do indígena no boi bumbá de Parintins. https://catalogodeteses.capes.gov.br/catalogo-teses/\#!/

Neira, M. G. \& Lippi, B. (2012). Tecendo a Colcha de Retalhos: a bricolagem como alternativa para a pesquisa educacional. Revista Educação e Realidade, $37,(2), 607-625$.

Santos, V. S. (2019). Cultura popular e o modo da vida do brincante: costurando linhas de vida na perspectiva das africanidades. Dissertação de mestrado, do Programa de Pós-Graduação em Educação da Universidade Federal de São Carlos, Campus Sorocaba, Sorocaba/SP.

Santomé, J. T. (2019). As culturas negadas e silenciadas no currículo. In: SILVA, T. T. Alienígenas na sala de aula: uma introdução aos estudos culturais em educação. (pp. 155-172), Vozes.

Silva, D. A. (2019). Escultura como registro da cultura popular. In. Andréia Paro do Nascimento et al (org.), Educação Profissional - Teoria e Experiências Profissionais. (pp. 96-109), Print Impressões Inteligentes.

Silva, D. A. (2021). Os atributos pedagógicos da cultura popular da fronteira Guajará-Mirim (Brasil) - Guayaramerín (Bolívia). Editora Lucel.

Silva, D. A. (2021). A cultura folclórica do boi-bumbá no Instituto Federal de Rondônia - IFRO/Campus Cacoal: proposições para pensar práticas pedagógicas interdisciplinares. Dissertação de Mestrado Profissional em Educação Escolar não-publicada, Programa de Pós-Graduação em Educação da Fundação Universidade Federal de Rondônia- UNIR, Porto Velho/RO.

Silva, T. T. (2014). A produção social da identidade e diferença. In: Identidade e diferença - A perspectiva dos Estudos Culturais. Org. Tadeu Tomas da Silva, (pp. 73-102), (15a ed.), Vozes.

Woodward, K. (2014). Identidade e diferença: uma introdução teórica e conceitual. In. Identidade e diferença - a perspectiva dos Estudos Culturais. Org. Tomaz Tadeu da Silva. (pp.7-72), (15a ed.), Vozes. 